\title{
Seasonal and Diurnal Patterns of Spore Dispersal by Leptosphaeria maculans from Canola Stubble in Relation to Environmental Conditions
}

\author{
X. W. Guo and W. G. D. Fernando, Department of Plant Science, University of Manitoba, Winnipeg, MB, Canada, \\ R3T $2 \mathrm{~N} 2$
}

\begin{abstract}
Guo, X. W., and Fernando, W. G. D. 2005. Seasonal and diurnal patterns of spore dispersal by Leptosphaeria maculans from canola stubble in relation to environmental conditions. Plant Dis. 89:97-104.

Seasonal and diurnal patterns of spore dispersal by Leptosphaeria maculans, which causes blackleg disease of canola, were studied in two consecutive field seasons using a 7-day Burkard spore sampler and rotorod impaction spore samplers. Ascospores of L. maculans were trapped from mid-June to the end of July, whereas pycnidiospores were trapped from mid-July until the end of July or early August. Ascospores and pycnidiospores were trapped between 9:00 P.M. and 4:00 A.M., when air temperatures were 13 to $18^{\circ} \mathrm{C}$ and relative humidity was $>80 \%$. Peak ascospore and pycnidiospore dispersal was associated with rain events. Peak ascospore dispersal was found to occur several hours after rainfall $\geq 2 \mathrm{~mm}$, and ascospore dispersal continued for approximately 3 days after such events. Peak pycnidiospore dispersal occurred during the same hours as rain events. More ascospores and pycnidiospores were carried in the direction of prevailing winds than in other directions. To the south of the inoculated area, the gradients of disease incidence and stem disease severity were -19.2 and $-0.8 \mathrm{~m}^{-1}$, respectively. Disease incidence and stem severity declined by $50 \% 12.5$ and $5.5 \mathrm{~m}$ from the inoculated area, respectively. To the north of the inoculated area, the gradients of disease incidence and stem severity were -21.5 and $-0.7 \mathrm{~m}^{-1}$, respectively. Disease incidence and stem severity declined by $50 \% 14.0$ and $5.2 \mathrm{~m}$ from the inoculated area, respectively. In 2001, ascospores and pycnidiospores were trapped within $25 \mathrm{~m}$ of the inoculated area, whereas pycnidiospores were trapped up to $45 \mathrm{~m}$ from the inoculated area.
\end{abstract}

Additional keywords: spore concentration, time of spore dispersal

Canola (Brassica napus L. and B. rapa L.), is one of the major oilseed crops grown worldwide. With significant expansion of acreage sown to canola during the past two decades, concern about blackleg, the most serious disease of canola, has increased $(3,4)$. Blackleg disease is caused by Leptosphaeria maculans (Desmaz.) Ces. \& De Not. (anamorph: Phoma lingam (Tode:Fr.) Desmaz.). The pathogen can attack all parts of the plant. Symptoms first appear on cotyledons and true leaves as dirty white to buff-colored lesions, round to irregular in shape, and dotted with numerous black pinhead-size pycnidia (19).

Ascospores are the most important primary inoculum contributing to the disease (10). They can be liberated from infested

Corresponding author: W. G. D. Fernando E-mail: D_Fernando@umanitoba.ca

This research was funded by Agri-Food Research and Development Initiative (ARDI) and Natural Sciences and Engineering Research Council of Canada (NSERC) through grants provided to D. Fernando.

Accepted for publication 7 September 2004.

DOI: 10.1094/PD-89-0097

(C) 2005 The American Phytopathological Society stubble for at least 3 years $(12,14,15)$. Pycnidiospores act as secondary inoculum after infection is established by ascospores and are believed to be spread by rain splash to other leaves and neighboring plants $(1,14,19)$.
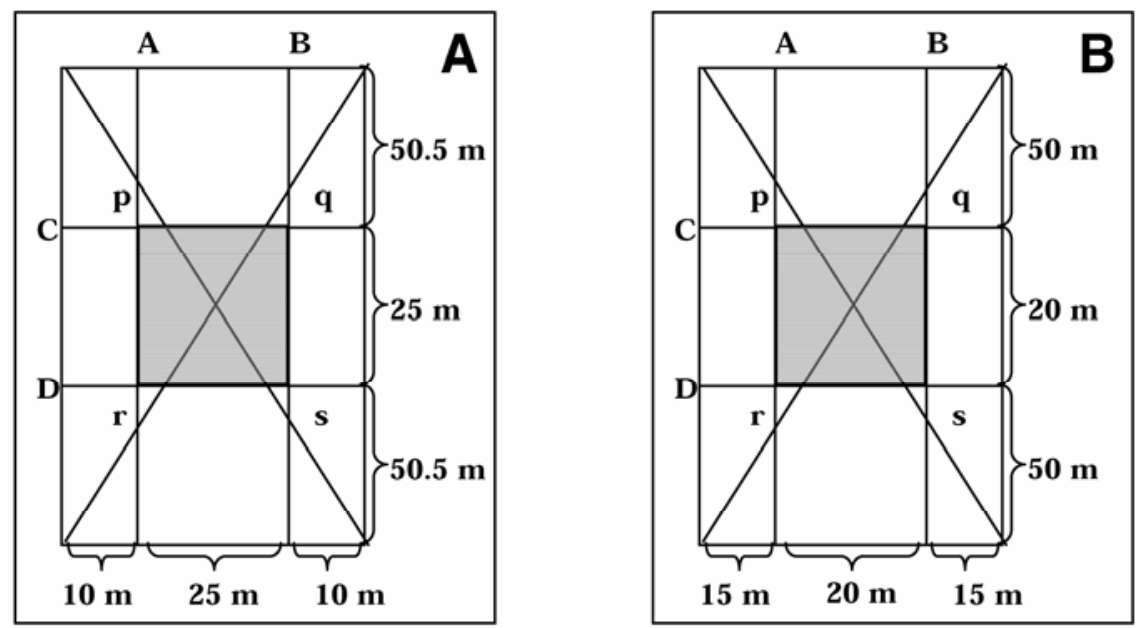

Fig. 1. Determination of the central inoculum source area of $\mathbf{A}$, plot 1 and $\mathbf{B}$, plot 2 . The central point of plot 1 was determined as the point of intersection of two diagonals of the plot. A 25-m line was determined in the middle of the short sides of the plot by measuring $10-\mathrm{m}$ lines from each end of the short side. Additional 25-m lines were determined in the middle of the long sides of the plot by measuring 50.5-m lines from each end of the long side. Four points of intersection, p, q, r and s, defined the central inoculated area of 25 by $25 \mathrm{~m}$ (shaded area). Similar measurements were made in plot 2. 
sulfate at $0.1 \mathrm{~g} /$ liter (Sigma-Aldrich, St. Louis) and $\mathrm{CaCO}_{3}$ at $0.75 \mathrm{~g} /$ liter (Fisher Scientific, Fair Lawn, NJ), and incubated in light at $24^{\circ} \mathrm{C}$. After 15 days, pycnidia were produced on the media; pycnidiospores were harvested in distilled sterilized water, filtered into 50-ml disposable sterile centrifuge tubes (Fisher Scientific, Pittsburgh, PA), and counted using a hemacytometer (Hausser Scientific Company, Horsham, PA). These tubes were stored in ice for $1 \mathrm{~h}$ during transport to the field site. Immediately before inoculation, the concentrated spores were diluted to a $1 \times 10^{7}$ spores/ml in distilled water. Tween 20 (Sigma-Aldrich) was added into the spore suspension at a ratio of $1 \mathrm{ml}$ of Tween 20 to $1,000 \mathrm{ml}$ of spore suspension.

Field plots and inoculation. The experiments were carried out in a 126-by-45$\mathrm{m}$ plot from 1999 to 2001 (plot 1) and in a 120-by-50-m plot from 2001 to 2002 (plot 2), at the Carman Research Station, Carman, Manitoba, Canada.

In plot 1, wheat was planted in 1997 and 1998. In 1999, the entire plot was planted to canola cv. Westar (susceptible to blackleg pathogen) at a seeding rate of $5 \mathrm{~kg} / \mathrm{ha}$
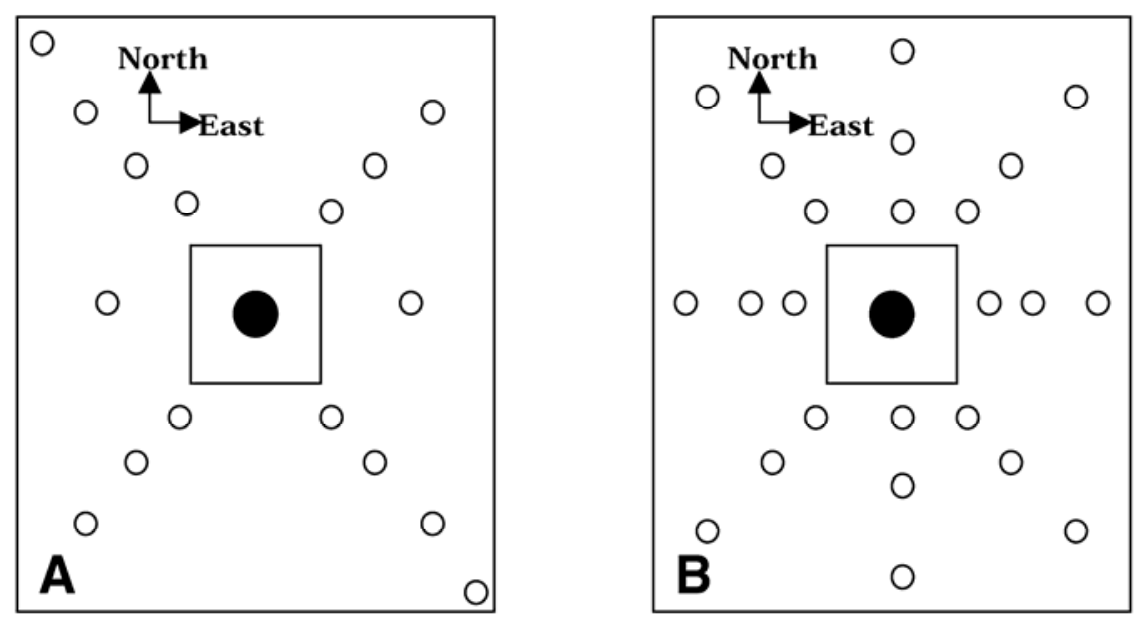

Fig. 2. Location of rotorod impaction spore samplers and a 7-day Burkard spore trap in A, plot 1 and B, plot 2. The small square areas in the center of plot 1 and plot 2 were the inoculated areas. The big closed circles in the plot centers represent the 7-day Burkard spore traps, and small open circles in different directions represent rotorod impaction spore samplers. on 30 May. The center of plot 1 was determined as the point of intersection of the two diagonals of the plot before seeding (Fig. 1A). A 25-m line was determined in the middle of the short side of the plot by measuring a $10-\mathrm{m}$ line from each end of the short side. Another 25-m line was determined in the middle of the long side of the plot by measuring a $50.5-\mathrm{m}$ line from each end of the long side. Four points of intersection, p, q, r, and s, defined a 25-by25- $\mathrm{m}$ area that was inoculated in the center of the plot. At the three-leaf stage, this area was uniformly inoculated using a backpack sprayer with a pycnidiospore suspension of PG-2 isolate $86-12$ at $1 \times 10^{7}$ spores/ml from 7:00 to 8:00 P.M. on 10 June. In fall 1999, canola in the plot was harvested; the central 25-by-25-m area was left untilled, whereas the area around this central area was tilled using a tiller with a tine harrow that reached a soil depth of 10 $\mathrm{cm}$. On 30 May 2000, the entire plot was planted to Westar at the same seeding rate as in 1999. In the fall of 2000, the plot was harvested, canola stubble in the 25-by-25$\mathrm{m}$ area was left untilled, and stubble in the rest of the plot was tilled as in 1999. On 1 June 2001, the plot was again planted to Westar. In plot 2, hemp and wheat were planted in 1999 and 2000, respectively. On 30 May 2001, the entire plot was planted to Liberty Link cv. 2153 (moderately susceptible to blackleg disease) at a seeding rate of $5 \mathrm{~kg} / \mathrm{ha}$. The central inoculum source area of 20 by $20 \mathrm{~m}$ was determined the same way as in plot 1 (Fig. 1B). At the three-leaf stage on 10 June, the central 20-
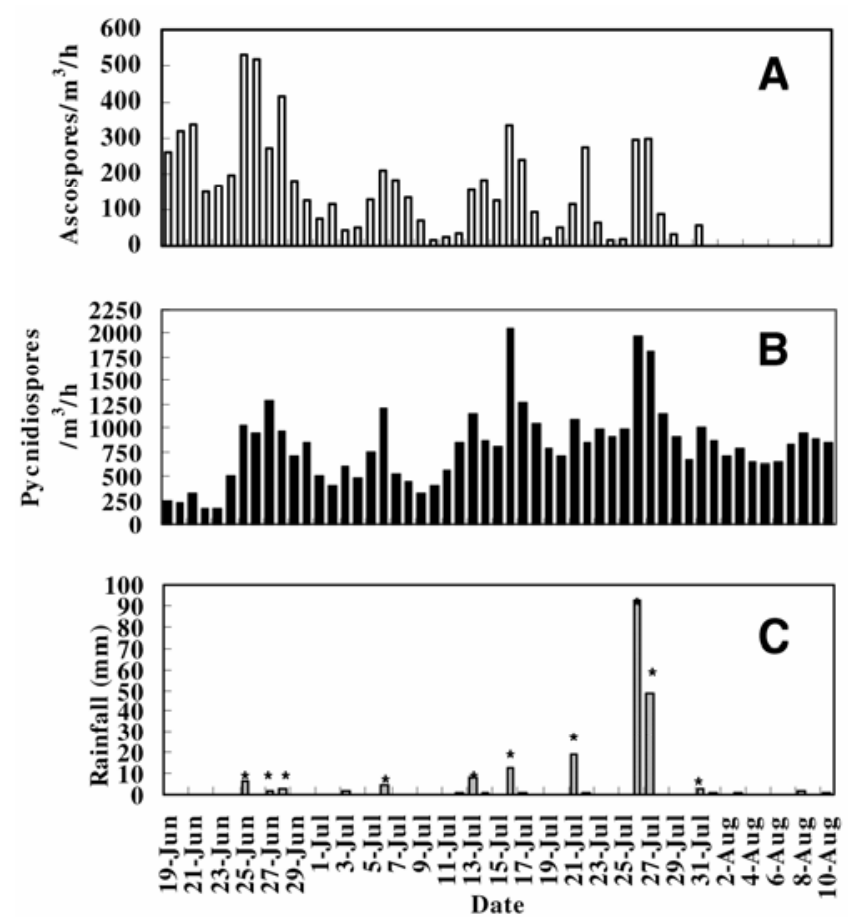

Fig. 3. Seasonal patterns of $\mathbf{A}$, ascospore and $\mathbf{B}$, pycnidiospore dispersal by Leptosphaeria maculans from a point source inoculum trapped by a Burkard 7-day spore trap, and $\mathbf{C}$, rain events in 2001; * on the rain bars represents rainfall of $\geq 2 \mathrm{~mm}$.
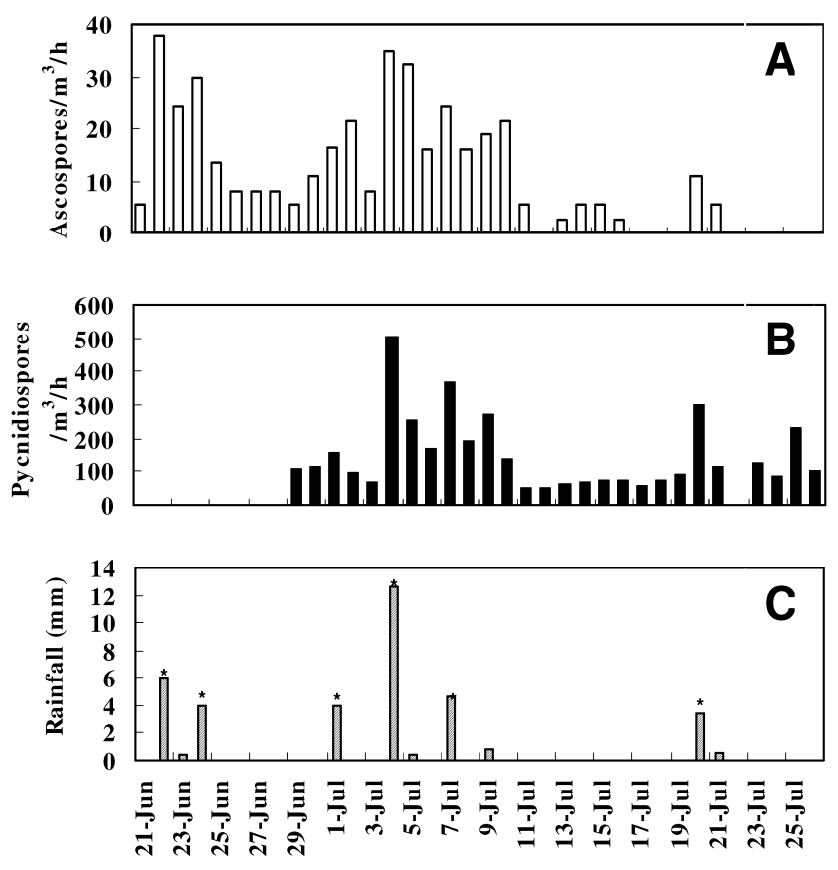

Date

Fig. 4. Seasonal patterns of $\mathbf{A}$, ascospore and $\mathbf{B}$, pycnidiospore dispersal by Leptosphaeria maculans from a point source inoculum trapped by a Burkard 7-day spore trap, and C, rain events in 2002; * on the rain bars represents rainfall of $\geq 2 \mathrm{~mm}$. 
by-20-m area was inoculated using the pycnidiospore suspension of PG-2 isolate $86-12$ at $1 \times 10^{7}$ spores/ml from 7:00 to 8:00 P.M. After harvesting the plot, the central area was left untilled while the remainder of the plot was tilled as in plot 1. On 1 June 2002, the entire plot was planted to $\mathrm{cv}$. LL 2153. There were no canola fields within $1 \mathrm{~km}$ of the two experimental plots from 1999 to 2002.

Spore sampling and weather data collecting. In 2001, rotorod impaction spore samplers (Aerobiology Company, Nepean, Ontario, Canada) were set up in plot 1 (Fig. 2A). Based on historical weather data at Carman, prevailing winds came from the northwest (NW) and the southeast (SE). Therefore, four spore samplers were placed $1,5,25$, and $45 \mathrm{~m}$ to the $\mathrm{NW}$ and SE of the edge of the inoculated area on the diagonals of the plot. Three spore samplers were placed 1,5 , and $25 \mathrm{~m}$ to the northeast (NE) and southwest (SW) of the edge of the inoculated area, and two spore samplers were placed $5 \mathrm{~m}$ east (E) and west $(\mathrm{W})$ from the side of the inoculated area to trap spores. A CR10 datalogger (Campbell Scientific, Logan, UT) was programmed to operate the rotorods for 5 $\mathrm{min} / \mathrm{h}$. A thin coat of petroleum jelly was brushed on each rotorod to catch spores and each rotorod was replaced every $24 \mathrm{~h}$. In addition, a 7-day Burkard spore trap (Burkard Scientific Ltd., Uxbridge, Middlesex, UK) was set up in the center of the inoculated area. The tape in the Burkard spore trap was coated with a thin layer of petroleum jelly and replaced weekly.

In 2002, rotorod impaction spore samplers were set up in plot 2 in N, NE, E, SE, $\mathrm{S}, \mathrm{SW}, \mathrm{W}$, and NW directions 1, 5, and 10 $\mathrm{m}$ from the perimeter of the 20-by-20-m inoculated area (Fig. 2B). A Burkard spore trap was set up in the center of the inoculated area as in 2001.

Rainfall, air temperature, relative humidity $(\mathrm{RH})$, and wind direction data were collected from the weather station at the Carman Research Station, which was located approximately $100 \mathrm{~m}$ to the east of the experimental plots.

Growth stage. In 2001 and 2002, the cotyledon stage of the crop occurred about 10 June, first to third leaf stages occurred between 14 and 18 June, third to sixth leaf stages occurred between 18 and 30 June, and sixth leaf to flowering stages were between 30 June and 10 July.

Measurement and analysis. Spore concentration based on the Burkard data was used for the analysis of daily and hourly spore dispersal. Each Burkard tape was divided into seven equal sections, each section representing 1 day. Each section then was divided into 24 divisions, each representing $1 \mathrm{~h}$. The area of one section (24 h) was 20 by $48 \mathrm{~mm}$; the area of one division ( $1 \mathrm{~h}$ ) was 2 by $20 \mathrm{~mm}$. Spores in five microscope fields $(\times 400)$, located at least $3.5 \mathrm{~mm}$ from each other, were
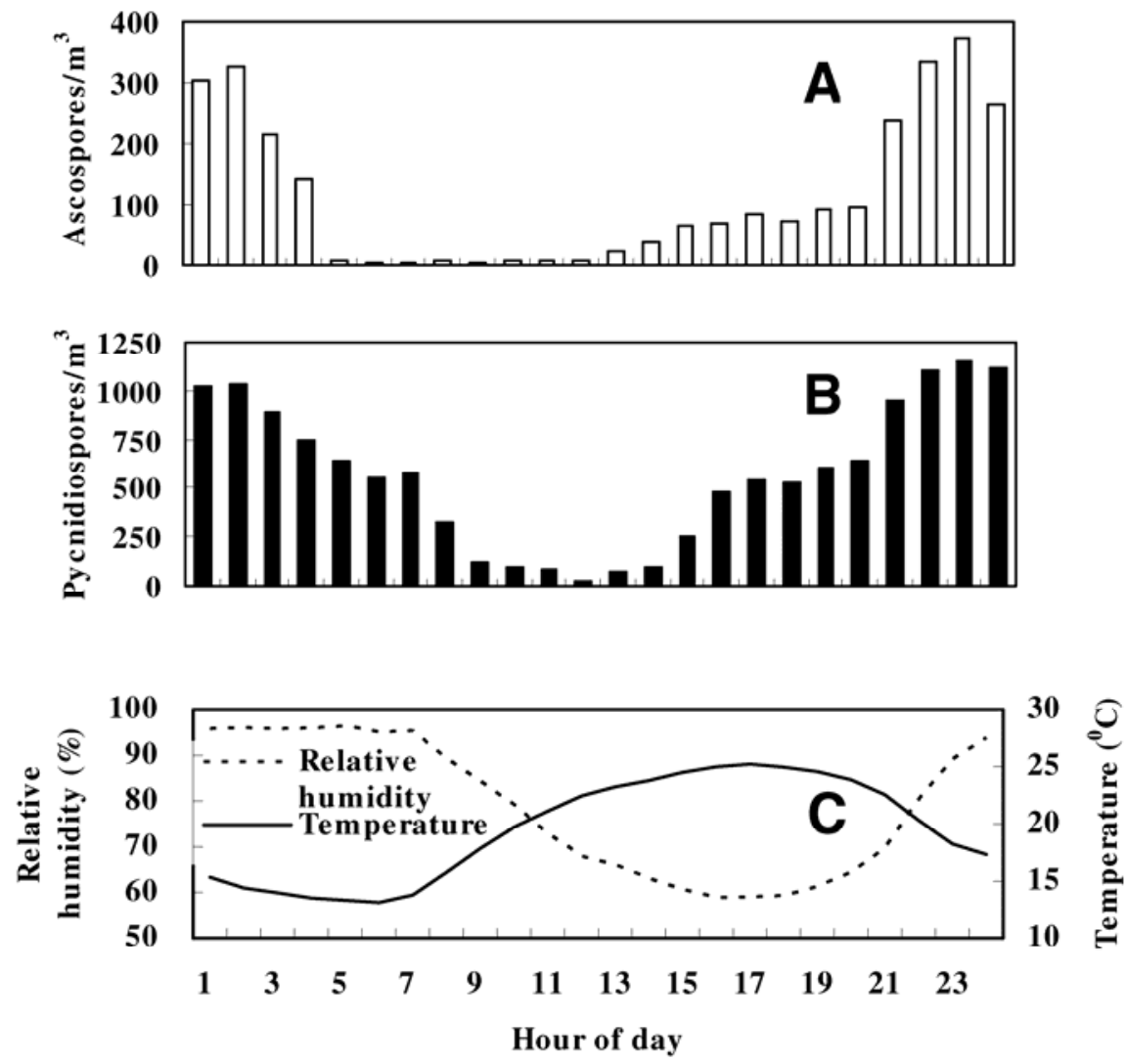

Fig. 5. Diurnal dispersal of $\mathbf{A}$, ascospores and $\mathbf{B}$, pycnidiospores by Leptosphaeria maculans in relation to $\mathbf{C}$, air temperature and relative humidity averaged over 34 days without rain from 19 June to 10 August 2001.
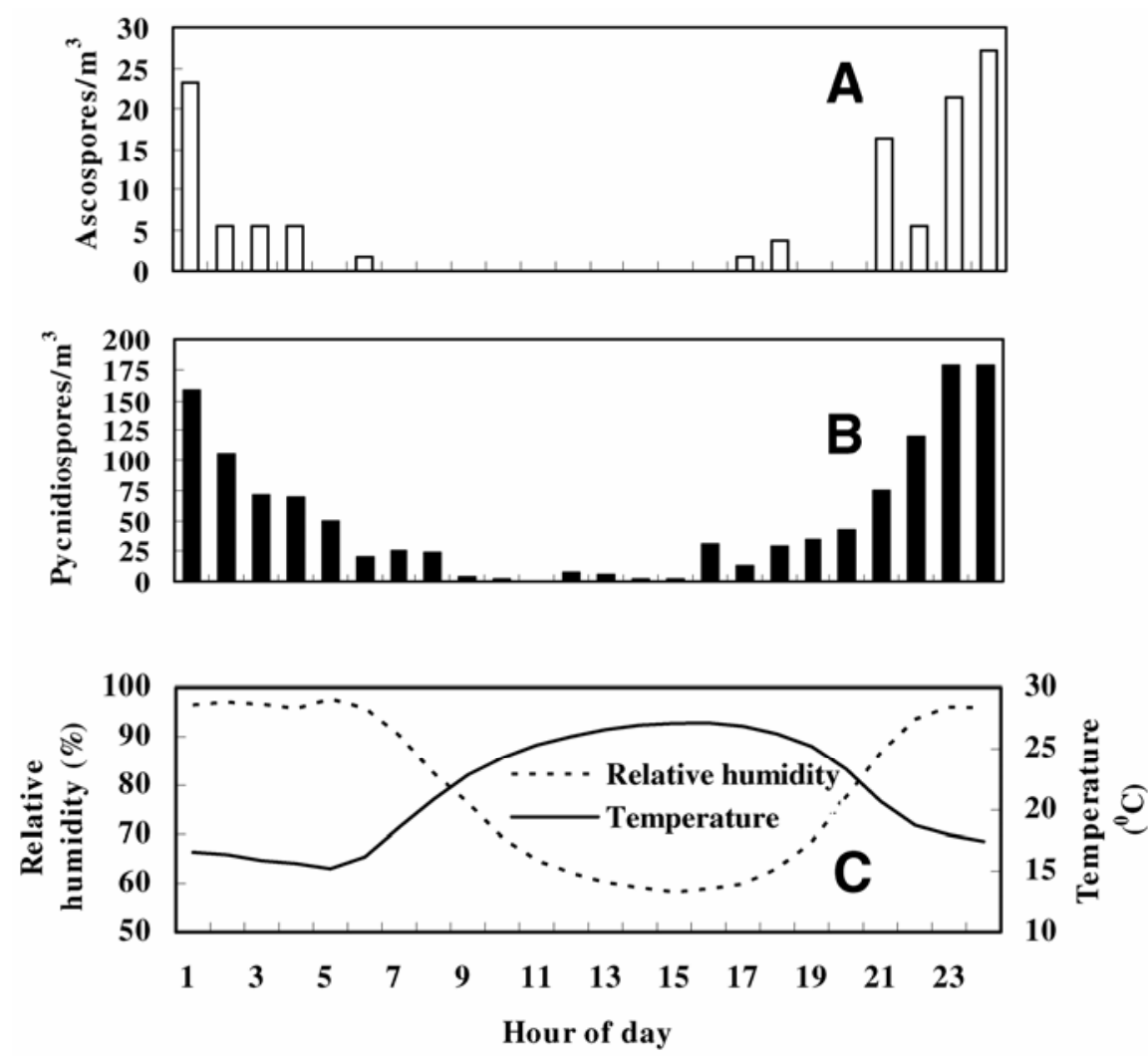

Fig. 6. Diurnal dispersal of $\mathbf{A}$, ascospores and $\mathbf{B}$, pycnidiospores by Leptosphaeria maculans in relation to $\mathbf{C}$, air temperature and relative humidity averaged over 26 days without rain from 21 June to 26 July 2002 . 
counted in each 1-h division. The area of each field was $0.20 \mathrm{~mm}^{2}$. The number of spores per five fields was converted into estimated numbers of spores per division and section. Spore concentration per hour in air was calculated as the number of spores per division divided by the throughput at the orifice of the Burkard trap, which was $0.6 \mathrm{~m}^{3} / \mathrm{h}$. Mean concen- tration per hour of spores on a certain day was calculated as total number of spores per section divided by the throughput ( 0.6 $\mathrm{m}^{3} / \mathrm{h}$ ) and $24 \mathrm{~h}$.

Spore concentration based on a rotorod spore sampler was used for analysis of spore release at different distances and in different directions from the inoculated area. Length of the rod for collecting
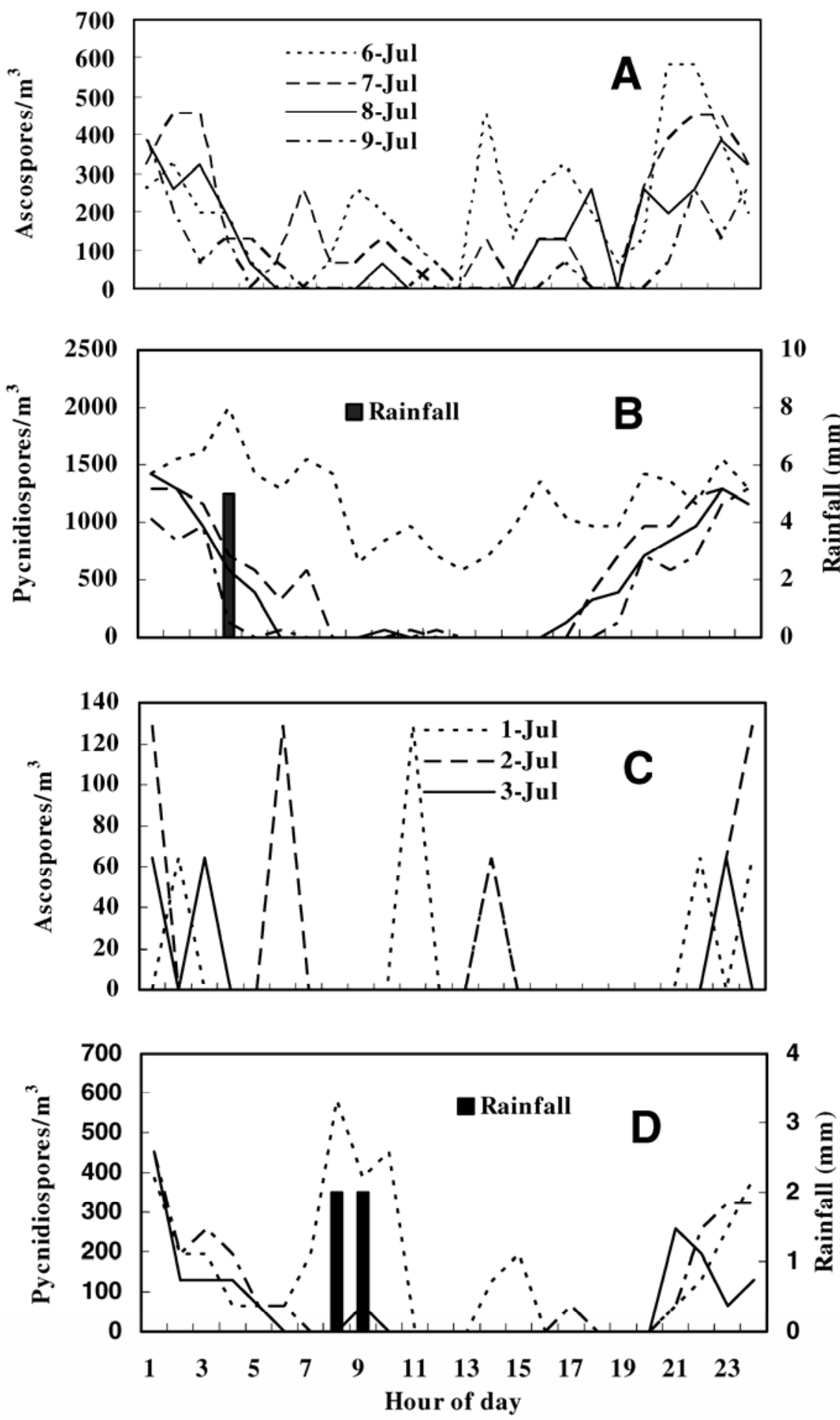

Fig. 7. Relationship between time of rain and $\mathbf{A}$, ascospore and $\mathbf{B}$, pycnidiospore dispersal on 6-9 July 2001. A rain event of $5 \mathrm{~mm}$ occurred at 4:00 a.m. on 6 June, and there was no rain on 7, 8, and 9 June. Relationship between time of rain and $\mathbf{C}$, ascospore and $\mathbf{D}$, pycnidiospore dispersal on 1-3 July 2002. Two rain events occurred between 8:00 and 9:00 a.m. on 1 July; rainfall for each hour was $2 \mathrm{~mm}$. There was no rain on 2 and 3 July.

spores was $20 \mathrm{~mm}$. The collecting face of a rod was divided into 15 fields. The spores in the 15 fields were counted under a microscope at $\times 400$. Mean concentration of spores per day was calculated as total number of spores on one rod divided by the following factors: rod rotations per minute $(2,400)$, the rotation constant (0.097), the sampling period in minutes per day (120 $\mathrm{min}$ ), and $24 \mathrm{~h}$.

Hourly mean temperature and $\mathrm{RH}$ data were obtained from a Vaisala HMP 35C Humicap (Campbell Scientific Canada Corp., Edmonton, Alberta, Canada) and a HMP 35A Humicap (Campbell Scientific Canada Corp.), respectively. The sensors measured temperature and $\mathrm{RH}$ once per minute; temperature and $\mathrm{RH}$ were averaged over 60 min. An AES Tipping Bucket Rain Gauge (Atmospheric Environment Service, Downsview, Ontario, Canada) was used to measure hourly rainfall.

Stem disease severity and incidence were assessed at the pod-filling stage of canola (seeds in a pod turn yellow) in plot 2 in 2002. The 120-by-50-m plot was divided into 120 10-by-5-m units. For each unit, plants were sampled in two transects, one in a NE-SW direction and the other in a NW-SE direction. Row spacing was 0.20 $\mathrm{m}$; therefore, 24 plants in each transect, approximately $0.45 \mathrm{~m}$ from each other, were sampled. Sampling started $0.45 \mathrm{~m}$ from the corner of a unit. Stem disease severity was graded using a 0 -to- 5 scale in which $0=$ no infection, $1=$ lesion area less than $25 \%$ of the cross-section area of the crown, $2=25$ to $50 \%, 3=51$ to $75 \%, 4=$ 76 to $100 \%$, and $5=$ plant dead (D. Fernando, unpublished data). Disease incidence was assessed as the number of infected plants divided by total number of plants sampled.

The distance from the outer edge of the central inoculated area to the point at which the disease incidence or severity declined by $50 \%\left(\mathrm{D}_{50}\right)$ was assessed. Gradient of disease spread, measured from the outer edge of the inoculated area, was estimated as reduction of disease incidence or severity per unit distance $\left(\mathrm{m}^{-1}\right)$.

Mean daily concentration of spores in a certain direction was calculated as the average concentration of spores dispersed from all rotorod spore samplers in this direction over all the sampling days. North wind was defined as $0^{\circ}, \mathrm{NE}$ wind was 0 to $89^{\circ}, \mathrm{E}$ wind as $90^{\circ}, \mathrm{SE}$ wind as 91 to $179^{\circ}$, $\mathrm{S}$ wind as $180^{\circ}$, SW wind as 181 to $269^{\circ}$, $\mathrm{W}$ wind as $270^{\circ}$, and NW wind as 271 to $359^{\circ}$. Prevailing wind direction on each day was determined as the direction in which wind blew during the most hours.

\section{RESULTS}

Seasonal spore dispersal in relation to rain events. In 2001 (plot 1), ascospores were trapped daily from 19 June to 31 July, except on 30 July (Fig. 3). Pycnidiospores were trapped every day from 19 
June to 10 August. A greater number of ascospores than pycnidiospores were trapped prior to 23 June. After 23 June, more pycnidiospores were trapped than ascospores. Peak numbers of ascospores were observed on 21,25 , and 28 June and $6,16,22,26$, and $27 \mathrm{July}$, and peak pycnidiospores were observed on 27 June and 6, 16, and 26 July when rain events occurred.

Peaks of ascospore and pycnidiospore dispersal were associated with rainfall $\geq 2$ mm (Fig. 3). Peaks were observed on the same day as rain or 1 day after rain events. Peak pycnidiospore dispersal occurred on the same days as rain events.

In 2002 (plot 2), ascospores and pycnidiospores were first dispersed on 21 June (three-leaf stage) and 29 June (sixleaf stage), respectively (Fig. 4). Rain events favored spore dispersal (Fig. 4). More ascospores were trapped by 11 July (flowering stage), and no ascospores were trapped after 22 July, 9 days earlier than in 2001. The highest numbers of pycnidiospores were trapped on 4 July (budding stage), when the highest amount of rain fell for the season. Effects of rainfall $\geq 2 \mathrm{~mm}$ in 2002 showed a trend similar to 2001 (Figs. 3 and 4). Peak numbers of ascospores were observed on the same day as rain or 1 day after rainfall events, and peak pycnidiospore dispersal occurred on the same days as rain events (Fig. 4).

Diurnal spore dispersal in relation to air temperature and RH. On days without rain in 2001, more ascospores and pycnidiospores were trapped between 9:00 P.M. and 4:00 A.M., when the temperatures were 13 to $18^{\circ} \mathrm{C}$ and $\mathrm{RH}>80 \%$, than at other times of day (Fig. 5). A similar trend was observed in 2002 (Fig. 6).

Relationship between time of rain and spores trapped on Burkard spore sampler. In 2001, the first peak of ascospore dispersal was observed $5 \mathrm{~h}$ after rain on 6 July; peak numbers of ascospores then were trapped $10,13,17$, and $18 \mathrm{~h}$ after rain on the same day (Fig. 7A and B). Ascospore numbers decreased in magnitude during the following 3 days. The highest peak of pycnidiospores was trapped at the same hour as the rainfall on 6 July; following this peak, spore dispersal occurred 3, 7, 12,16 , and $19 \mathrm{~h}$ after rain on the same day (Fig. 7B). Only a few pycnidiospores were trapped between 8:00 A.M. and 5:00 P.M. on 7, 8, and 9 July. In July 2002, similar trends were observed as in 2001. The first peak of ascospores was observed $1 \mathrm{~h}$ after rain ended on 1 July (Fig. 7C and D). Additional ascospores were trapped sporadically on 2 July, and fewer spores were trapped on 3 July (Fig. 7C). The highest peak of pycnidiospores was observed between 8:00 and 9:00 A.M. during the rain event on 1 July; however, continuation of the same rain event between 9:00 and 10:00 A.M. resulted in slightly lower spore
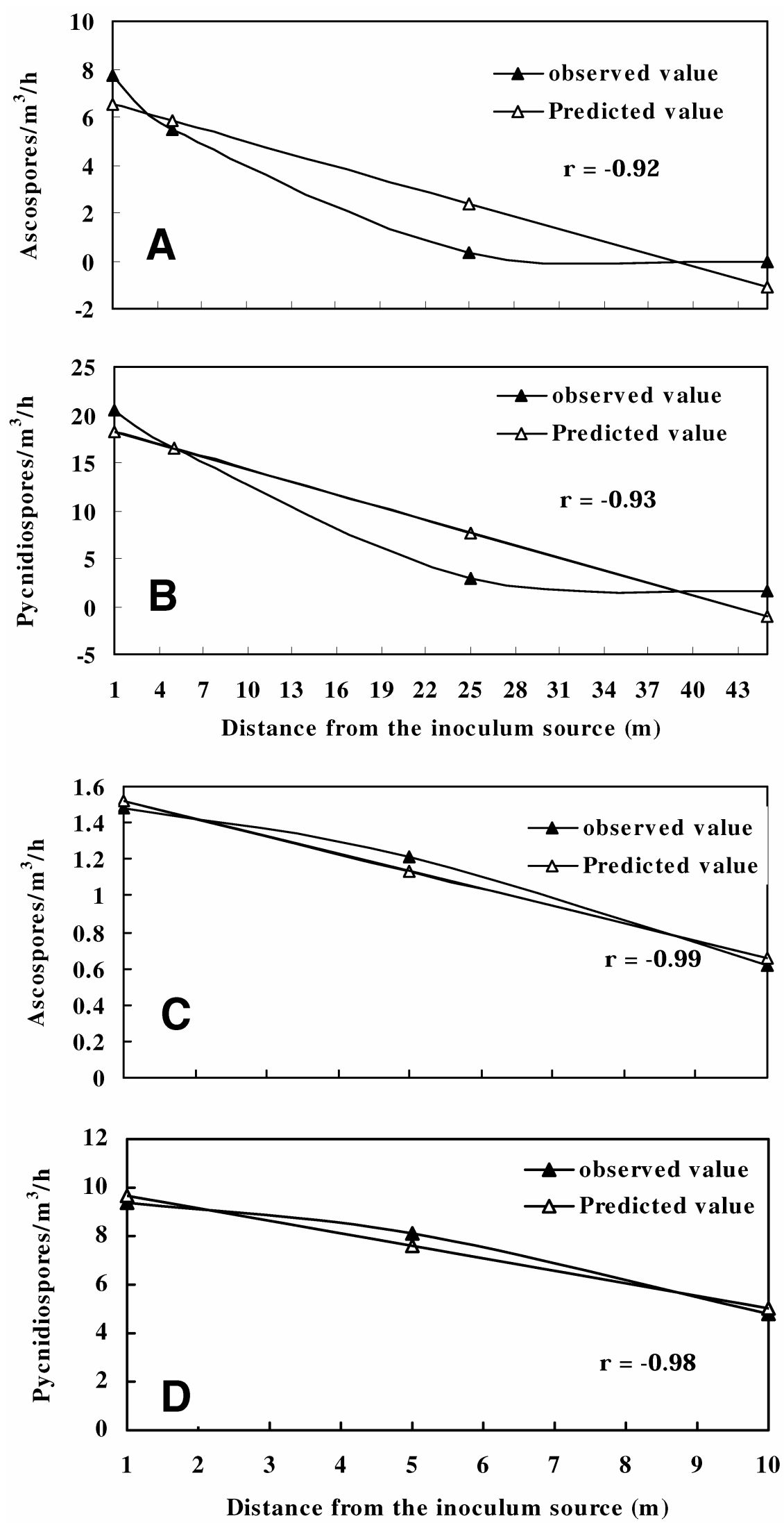

Fig. 8. Relationship between $\mathbf{A}$, ascospore and $\mathbf{B}$, pycnidiospore concentrations and distance from the inoculum source in 2001. The rate equation for ascospore concentration was $y=-0.1741 x+6.7055$ and for pycnidiospore concentration was $y=-0.4394 x+18.6710$, where $y$ is spore concentration (spores $/ \mathrm{m}^{3} / \mathrm{h}$ ) and $x$ is distance $(\mathrm{m})$ from the central inoculum source area. Relationship between $\mathbf{C}$, ascospore and $\mathbf{D}$, pycnidiospore concentrations and distance from the inoculum source in 2002 . The rate equation for ascospore concentration was $y=-0.0965 x+1.6179$ and for pycnidiospore concentration was $y=$ $-0.5163 x+10.1800$, where $y$ is spore concentration (spores $\left./ \mathrm{m}^{3} / \mathrm{h}\right)$, and $x$ is distance $(\mathrm{m})$ from the central inoculum source area. All lines and curves were drawn using Trendline in Microsoft Excel 2000. 
numbers (Fig. 7D). Pycnidiospore capture increased somewhat $1 \mathrm{~h}$ after the rain event ended. Fewer pycnidiospores were trapped on 2 and 3 July.

Relationship between spore concentration and distance from the inoculum source. A higher number of ascospores and pycnidiospores were trapped within 25 $\mathrm{m}$ of the central inoculated area than at greater distances in 2001 (Fig. 8A and B), and within $10 \mathrm{~m}$ from the inoculated area in 2002 (Fig. 8C and D). The gradients of ascospore and pycnidiospore concentrations were -2.8 and $-7.0 \mathrm{~m}^{-1}$, respectively, in 2001 , and -0.4 and $-2.3 \mathrm{~m}^{-1}$ in 2002 .

Ascospore and pycnidiospore concentrations were negatively correlated with the distance from the central inoculum source area in 2001 (ascospore, $r=-0.92$; pycnidiospore, $r=-0.93$; Fig. $8 \mathrm{~A}$ and $\mathrm{B}$ ) and 2002 (ascospore, $r=-0.99$; pycnidiospore, $r=-0.98$; Fig. $8 \mathrm{C}$ and D).

Effect of wind direction on spore dispersal. In 2001, prevailing winds were from the SE and SW. Higher ascospore and pycnidiospore concentrations were observed downwind from the direction of prevailing winds (Fig. 9A and B). Higher ascospore and pycnidiospore concentrations were observed in traps in the NW and NE corners of the experimental plot when winds came from the SE, SW, and both SE and $\mathrm{SW}(\mathrm{SE}+\mathrm{SW})$.
In 2002, the prevailing wind directions were SE and SW+SE. A similar effect of wind direction on ascospore and pycnidiospore dispersal was observed in 2002 as in 2001 (Fig. 9C and D). The highest ascospore and pycnidiospore concentration was in the SE direction when wind was from NW, in NW and W with a SE wind, in SE and SW with a NW+NE wind, in SW and NW with the NE+SE wind, and $\mathrm{NW}$ and NE with the SW+SE wind (Fig. 9C and D).

Disease spread in the field. Disease incidence and stem disease severity decreased with distance from the central inoculum source area (Table 1; Fig. 10). The gradients of disease incidence and stem disease severity were steeper to the south of the central inoculum source area than to the north (Table 1).

\section{DISCUSSION}

To our knowledge, this is the first report of seasonal and diurnal dispersal patterns of ascospores and pycnidiospores by the blackleg pathogen from canola stubble under the weather conditions of western Canada. This study revealed that the period of ascospore and pycnidiospore dispersal of the blackleg pathogen coincided with the susceptible growth stages of canola, thereby explaining how severe stem canker, one of the most important factors limiting canola yield, may occur under favorable weather conditions, and providing a foundation for management of the blackleg disease in western Canada. Although ascospores have been implicated as primary inoculum, this is the first report to show the importance of $\mathrm{RH}$ and wind on dissemination of ascospores and pycnidio-

Table 1. Blackleg disease spread in the field in $2002^{\mathrm{a}}$

\begin{tabular}{lcccc}
\hline Direction & $\begin{array}{c}\text { Gradient of disease } \\
\text { incidence }\left(\mathbf{m}^{\mathbf{- 1}}\right)\end{array}$ & $\begin{array}{c}\text { Gradient of stem } \\
\text { disease severity }\left(\mathbf{m}^{\mathbf{- 1}}\right)\end{array}$ & $\begin{array}{c}\mathbf{D}_{\mathbf{5 0}} \text { disease } \\
\text { incidence }(\mathbf{m})\end{array}$ & $\begin{array}{c}\mathbf{D}_{\mathbf{5 0}} \text { stem disease } \\
\text { severity }(\mathbf{m})\end{array}$ \\
\hline South & -21.45 & -0.79 & 12.5 & 5.5 \\
North & -19.22 & -0.70 & 14.0 & 5.2 \\
\hline
\end{tabular}

${ }^{a}$ Gradient of disease incidence $=$ reduction of disease incidence per unit distance $\left(\mathrm{m}^{-1}\right)$. Gradient of stem disease severity $=$ reduction of stem disease severity per unit distance $\left(\mathrm{m}^{-1}\right) . \mathrm{D}_{50}$ disease incidence $=$ distance from the outer edge of the central inoculum area to where the disease incidence declines by $50 \% . \mathrm{D}_{50}$ stem disease severity = distance from the outer edge of the central inoculum area to where the stem disease severity declines by $50 \%$. South and North $=$ to the south and north, respectively, of the central inoculated area.
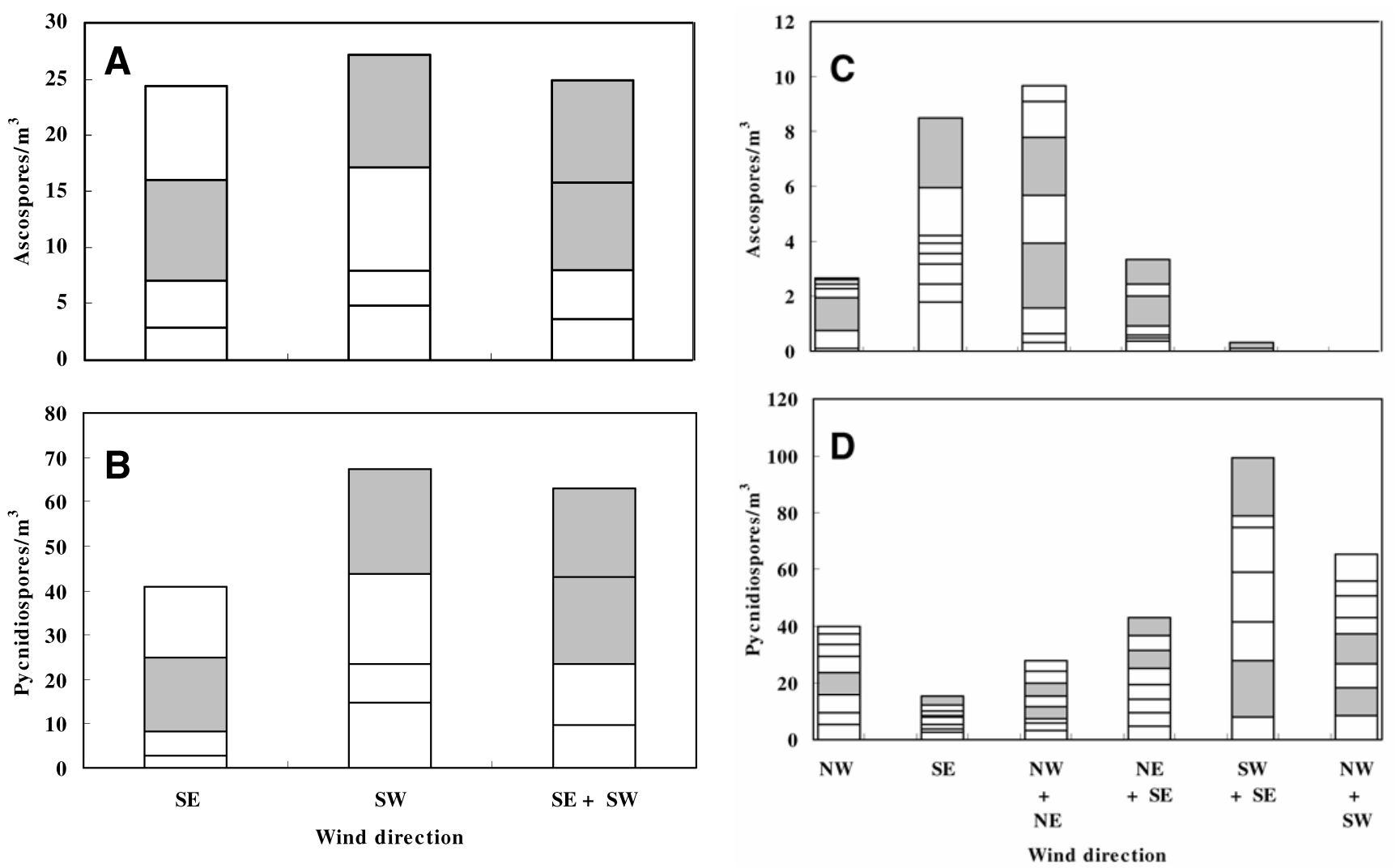

Fig. 9. Mean daily concentration of A, ascospores and B, pycnidiospores trapped along transects to the northeast (NE), northwest (NW), southwest (SW), and southeast (SE) of the central inoculated area in a 126-by-45-m plot with the wind coming from SE, SW, and SW+SE over 53 days in 2001 . A closed box in a bar represents spores captured downwind from the direction noted on the $\mathrm{X}$ axis and open boxes represent the other directions. Mean daily concentration of $\mathbf{C}$, ascospores and $\mathbf{D}$, pycnidiospores trapped along a transect to the NW, SE, NW+NE, NE+SE, SW+SE, and NW+SW of the central inoculated area in a 120-by-50-m plot with the wind coming from NW, W, SW, S, SE, E, NE, and N over 36 days in 2002. 

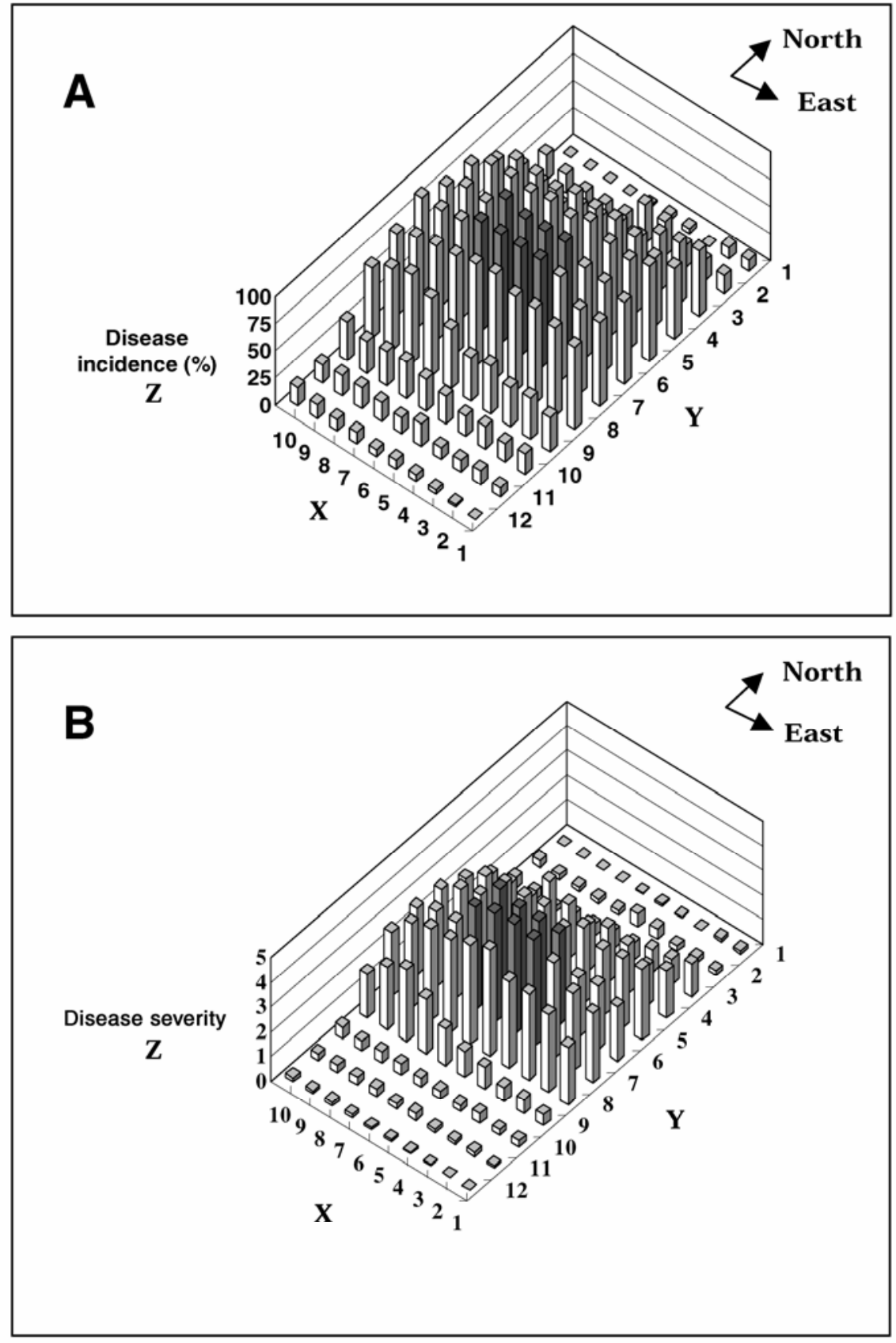

Fig. 10. Disease incidence and severity at maturity in the field in 2002. The $X$ and $Y$ axes represent the field plot ( 50 by $120 \mathrm{~m}$, respectively) of the graph, and the $\mathrm{Z}$ axis represents $\mathbf{A}$, disease incidence or $\mathbf{B}$, severity. The numbers on the $\mathrm{X}$ and $\mathrm{Y}$ axes indicate the row and column, respectively, in which a 5-by$10-\mathrm{m}$ unit area was investigated for disease incidence and severity. The dark gray bars in the center of the figure represent the central inoculum source area. Stem disease severity was rated on a 0 to 5 scale where $0=$ no infection, $1=$ lesion area less than $25 \%$ of cross-section area of crown, $2=25$ to $50 \%, 3$ $=51$ to $75 \%, 4=76$ to $100 \%$, and $5=$ plant dead. Disease incidence was expressed as [(number of stem-infected plants)/(total number of plants sampled) $] \times 100$. spores in the blackleg disease of canola The relationship between spore dispersal and disease was established through spore gradients. There was a diurnal dispersal pattern of ascospores and pycnidiospores from 9:00 P.M. to 4:00 A.M. when temperatures were 13 to $18^{\circ} \mathrm{C}$ and $\mathrm{RH}$ was $>80 \%$. Peak ascospore dispersal occurred several hours after rainfall $\geq 2 \mathrm{~mm}$, and persisted during the following 3 days. Peak pycnidiospore dispersal occurred at the same hours as rain events.

Petrie (18) reported in a survey that ascospore dispersal often began on canola stubble in June in Saskatchewan, but few ascospores were trapped at the end of July. Hershman and Perkins (9) showed that infected stubble dispersed ascospores 1 week after harvest, and dispersed significant quantities of ascospores in the fall and winter months following canola crop harvest in Kentucky. In Europe, peak ascospore dispersal often occurred in September, October, or November (8); whereas, in Australia, the peak occurred from June through August $(2,12-14)$. These patterns of ascospore dispersal were dependent on different weather conditions and crop planting systems. In Australia, summer was hot and dry, and spring canola was grown from May to November (12). In Europe, wet and mild weather was predominant, and winter canola was grown in most areas from September to May (8). After a long, cold winter in Canada, spring canola is grown during hot, dry summers from mid-May to the end of August. Maturation of pseudothecia and decomposition of canola stubble could differ regionally in response to weather conditions (17).

There was a large difference in the amount of spores trapped and time of spore dispersal between 2001 and 2002. The optimal temperature and $\mathrm{RH}$ for formation of pseudothecia and release of ascospores were $14^{\circ} \mathrm{C}$ and $100 \%$, respectively $(16,17)$. January to July 2001 was characterized by temperatures closer to $14^{\circ} \mathrm{C}$, higher $\mathrm{RH}$, and greater precipitation than the same periods in 2002 (Table 2). As a result, the number of ascospores dispersed in 2001 was greater than in 2002. The fact that more ascospores were dispersed in 2001 compared with 2002 caused more lesions on canola plants and a greater number of pycnidiospores. Similarly, more numerous rainfall events in July 2001 may

Table 2. Mean monthly temperature, relative humidity, and total precipitation from January to August 2001 and 2002

\begin{tabular}{|c|c|c|c|c|c|c|c|c|}
\hline Year & January & February & March & April & May & June & July & August \\
\hline \multicolumn{9}{|c|}{ Temperature $\left({ }^{\circ} \mathrm{C}\right)$} \\
\hline 2001 & -11.4 & -17.4 & -6.0 & 4.1 & 12.7 & 16.4 & 19.6 & 18.5 \\
\hline 2002 & -12.5 & -8.9 & -10.3 & 2.0 & 5.7 & 18.3 & 21.6 & 17.4 \\
\hline \multicolumn{9}{|c|}{ Relative humidity (\%) } \\
\hline 2001 & 91.5 & 83.2 & 88.1 & 64.2 & 74.0 & 76.4 & 81.2 & 74.9 \\
\hline 2002 & 86.8 & 83.4 & 76.5 & 73.5 & 67.2 & 77.5 & 74.9 & 80.3 \\
\hline \multicolumn{9}{|c|}{ Precipitation (mm) } \\
\hline 2001 & 215.6 & 10.8 & 13.8 & 69.2 & 162.9 & 30.0 & 160.4 & 19.0 \\
\hline 2002 & 11.9 & 5.7 & 20.0 & 30.2 & 103.6 & 141.0 & 30.0 & 106.4 \\
\hline
\end{tabular}


account for a greater number of pycnidiospores trapped than in July 2002.

Pycnidiospore dispersal on days without rain and occasional pycnidiospore dispersal several hours after rain events also were noted in our study. Pycnidiospore dispersal under high moisture conditions without rain may have been associated with the presence of dew. Peaks of ascospore dispersal following rain events may have resulted from time lags in pseudothecial maturity following these events.

Our study showed that ascospores of $L$. maculans could be dispersed to a distance of $25 \mathrm{~m}$ from the inoculum source. However, pycnidiospores were trapped up to 45 $\mathrm{m}$ from the inoculum source. Once ascospores establish infections in canola, pycnidiospores can be dispersed by both rain splash $(5-7,11)$ and wind to greater distances. This may point to the fact that ascospores may be responsible for primary infection and pycnidiospores contribute to secondary infection. According to our results, few ascospores and pycnidiospores of L. maculans likely would have reached the experimental plots from external sources, because there were no canola fields within $1 \mathrm{~km}$. In the management of blackleg disease, it is recommended that canola crops should be planted at least 50 to $100 \mathrm{~m}$ from each other.

Results of the present study will help to clarify the process of spore release and spread. An understanding of all these factors, especially temperature, $\mathrm{RH}$, and rainfall, that play important roles in affecting spore dispersal will be useful in modeling and forecasting epidemics of blackleg disease.
ACKNOWLEDGMENTS

We thank P. Parks and A. Iverson for assisting in the fieldwork, and M. Ballance and K. Prince for proofreading the manuscript.

\section{LITERATURE CITED}

1. Barbetti, M. J. 1976. The role of pycnidiospores of Leptosphaeria maculans in the spread of blackleg disease in rape. Aust. J. Exp. Anim. Husb. 16:911-914.

2. Bokor, A., Barbetti, M. J., and Brown, A. G. P. 1975. Blackleg of rapeseed. J. Agric. West. Aust. 16:7-10.

3. Fernando, W. G. D., and Chen, Y. 2003. First Report on the presence of Leptosphaeria maculans pathogenicity group-3, causal agent of blackleg of canola in Manitoba. Plant Dis. $87: 1268$, 2003; published on-line as D-2003$0808-02 \mathrm{~N}$.

4. Fernando, W. G. D., Parks, P. S., Tomm, G., Viau, L. V., and Jurke, C. 2003. First report of the blackleg disease caused by Leptosphaeria maculans on canola in Brazil. Plant Dis. 87:314 on-line D-2003-0117-01N

5. Fitt, B. D. L., Creighton, N. F., Lacey, M. E., and McCartney, H. A. 1986. Effects of rainfall intensity and duration on dispersal of Rhynchosporium secalis conidia from infected barley leaves. Trans. Br. Mycol. Soc. 86:611-618.

6. Fitt, B. D. L., McCartney, H. A., and Walklate, P. J. 1989. The role of rain in dispersal of pathogen inoculum. Annu. Rev. Phytopathol. 27:241-270.

7. Fitt, B. D. L., Walklate, P. J., McCartney, H. A., Bainbridge, A., Creighton, N. F., Hirst, J. M., Lacey, M. E., and Legg, B. J. 1986. A rain tower and wind tunnel for studying the dispersal of plant pathogens by rain and wind. Ann. Appl. Biol. 109:661-671.

8. Gladders, P., and Musa, T. M. 1980. Observations on the epidemiology of Leptosphaeria maculans stem canker in winter oilseed rape. Plant Pathol. 29:28-37.

9. Hershman, D. E., and Perkins, D. M. 1995. Etiology of canola blackleg in Kentucky and seasonal discharge patterns of Leptosphaeria maculans ascospores from infected canola stubble. Plant Dis. 79:1225-1229.

10. Howlett, B. J., Idnurm, A., and Pedras, M. S. C. 2001. Leptosphaeria maculans, the causal agent of blackleg disease of Brassicas. Fungal Genet. Biol. 33:1-14.

11. Madden, L. V. 1997. Effects of rain on splash dispersal of fungal pathogens. Can. J. Plant Pathol. 19:225-230.

12. McGee, D. C. 1974. The seasonal pattern of ascospore discharge of Leptosphaeria maculans. Aust. Plant Pathol. Soc. Newsl. 3:27.

13. McGee, D. C. 1974. The application of findings from surveys of the incidence of blackleg of rapeseed in Victoria. Aust. Plant Pathol. Soc. Newsl. 3:27.

14. McGee, D. C. 1977. Blackleg (Leptosphaeria maculans (Desm.) Ces. et de Not.) of rapeseed in Victoria: Sources of infection and relationship between inoculum, environmental factors and disease severity. Aust. J. Agric. Res. 28:53-62.

15. McGee, D. C., and Petrie, G. A. 1978. Variability of Leptosphaeria maculans in relation to blackleg of oilseed rape. Phytopathology 68:625-630.

16. Pérès A., Poisson, B., Le Sourne, V., and Maisonneuve, C. 1999. Leptosphaeria maculans: Effect of temperature, rainfall and humidity on the formation of pseudothecia. Proc. 10th Int. Rapeseed Congr. Canberra, Australia.

17. Petrie, G. A. 1994. Effects of temperature and moisture on the number, size and septation of ascospores produced by Leptosphaeria maculans (blackleg) on rapeseed stubble. Can. Plant Dis. Surv. 74(2):141-151.

18. Petrie, G. A. 1995. Patterns of ascospore discharge by Leptosphaeria maculans (blackleg) from 9- to 13-month-old naturally-infected rapeseed/canola stubble from 1977 to 1993 in Saskatchewan. Can. Plant Dis. Surv. 75(1):35-43.

19. Sawatsky, W. M. 1989. Evaluation of screening techniques for resistance to Leptosphaeria maculans and genetic studies of resistance to the disease in Brassica napus. Page 3-18 in: Master's thesis, University of Manitoba, Canada. 